Article

\title{
Documentary and Cognitive Theory: Narrative, Emotion and Memory
}

Ib Bondebjerg

Department of Media, Cognition and Communication, University of Copenhagen, Karen Blixens Vej 4, 2300 Copenhagen S, Denmark; E-Mail: bonde@hum.ku.dk

\section{How to Cite this Article}

Bondebjerg, I. (2014). Documentary and Cognitive Theory: Narrative, Emotion and Memory. Media and Communication, 2(1), 13-22.

\section{Copyrights}

(C) 2014 by the author; licensee Cogitatio (Lisbon, Portugal). This article is licensed under a Creative Commons Attribution 4.0 International License (CC BY).

\section{Published by:}

\section{COGITATIO}

www.cogitatiopress.com

\section{About the Journal}

Media and Communication is an international open access journal dedicated to a wide variety of basic and applied research in communication and its related fields. It aims at providing a research forum on the social and cultural relevance of media and communication processes.

www.cogitatiopress.com/mediaandcommunication

\section{Editors-in-Chief}

Professor Bradley Greenberg, Departments of Communication and Telecommunication, Information Studies and Media, Michigan State University, USA

Professor Elisabeth Klaus, Department of Communication, University of Salzburg, Austria

\section{Managing Editor}

Mr. António Vieira, Media and Communication, Cogitatio Press, Portugal 
Article

\title{
Documentary and Cognitive Theory: Narrative, Emotion and Memory
}

\author{
Ib Bondebjerg \\ Department of Media, Cognition and Communication, University of Copenhagen, Karen Blixens Vej 4, \\ 2300 Copenhagen S, Denmark; E-Mail: bonde@hum.ku.dk
}

Submitted: 15 October 2013 | In Revised Form: 18 December 2013 | Accepted: 11 March 2014 |

Published: 9 April 2014

\begin{abstract}
This article deals with the benefits of using cognitive theory in documentary film studies. The article outlines general aspects of cognitive theory in humanities and social science, however the main focus is on the role of narrative, visual style and emotional dimensions of different types of documentaries. Dealing with cognitive theories of film and media and with memory studies, the article analyses how a cognitive approach to documentaries can increase our understanding of how documentaries influence us on a cognitive and emotional level and contribute to the forming of our social and cultural imagination. The article analyses case studies of documentaries dealing with climate change and the environment and documentaries dealing with social history.
\end{abstract}

\section{Keywords}

cognitive theory; documentary and climate change; documentary genres; emotions; historical documentary; memory; narrative; social and cultural imagination

\section{Issue}

This article is part of a regular issue of Media and Communication, edited by Professor Bradley Greenberg (Michigan State University, USA) and Professor Elisabeth Klaus (University of Salzburg, Austria).

(C) 2014 by the author; licensee Cogitatio (Lisbon, Portugal). This article is licensed under a Creative Commons Attribution 4.0 International License (CC BY).

\section{Introduction}

Over the last two decades cognitive studies have moved to a more prominent place in both humanities and social science. There have been studies of creativity in general (Fauconnier \& Turner, 2002; Turner, 2006), in literary studies (Turner, 1998), in linguistics (Lakoff \& Johnson, 1980), philosophy (Lakoff \& Johnson, 1999), sociology and political studies (Brothers, 1997; Westen, 2007; Zerubavel, 1999), and in film studies (Grodal, 2009; Plantinga, 2009; Plantinga \& Smith 1999). What all these cognitive approaches to social and cultural phenomenon have in common is a fundamental challenge to the social constructivism theory, the attempt to base the analysis of human and social interaction and communication on an embodied understanding of who we are. There is a clear ambition in cognitive theory to try to understand to what extend human phenomena are defined by universal and biological dimensions and how these dimensions interact with and are influenced by social and cultural conditions and historical change.

Cognitive theory is based on the theory of evolution, and evolution clearly shows that we adapt to change over time, but also that some basic features remain fairly stable. Cognitive theory is not about eliminating the need for cultural and social research into art, media and communication, it is not about substituting culture with nature. On the contrary, as for instance, Brothers has put it (Brothers, 1997, xxi-xii), it is about bridging the 'gulf between biology and culture' between the social and cultural mind and the brain and body as a biological phenomenon. We need to see humans as both biological and cultural creatures, because-besides everything else humans and our brain and body are-we are also very much social and communicative creatures. We are storytelling animals (Gottschall, 2012), we think and speak through highly embodied metaphors (Lakoff \& Johnson, 1980) and our 
emotional capacities are extremely central for our cognitive and rational activities and arguments (Damasio, 1994). Society and culture shapes the human mind, but our brain and body-our whole biological structurecomes with structures, dispositions and biological functions and mechanism that also, to a large degree, influence the way we experience reality and communicate about it. Narrative structures are not just cultural and historical constructions, and neither are emotions or the structures of language. Variations however of these very basic elements of our mind and body are incredibly rich and are the result of historical and specific social and cultural circumstances.

\section{Film Studies, Cognitive Theory and Documentary}

Although film studies in general have been rather strongly influenced by cognitive theory, documentary film theory and film analysis has so far not been very influenced by the cognitive turn. Bordwell and Thompson (2001) have done some work on the more basic genres of documentary, influenced by both formalism and cognitive theory, and Carl Plantinga developed his approach more broadly in his seminal work Rhetoric and Representation in the Non-fiction Film (Plantinga, 1997). Also Belinda Smaill has written a useful book on documentary and emotion, although not based on cognitive theory (Smaill, 2010). In this article I want to move the cognitive, theoretical approach to documentary film a bit further, by focusing on some of the basic assumptions already put forward in many cognitive studies on the relation between cognition, emotions, narratives and memory. Since these assumptions are based on very fundamental processes in our biological, cultural and social brain, they have importance for both social and cultural processes in general and for genres of both fiction and non-fiction. If narrative structures and emotions are basic dimensions of the way we understand and communicate about the world, they are also part of documentary genres, even though such genres have a specific relation to reality and to a large degree seem to perform a function, which Bill Nichols has called 'actively making a case or an argument' (Nichols, 2001, p. 4). In many ways we can see documentary as a rhetorical form, as a story with some kind of argument inside. We expect documentary films to tell us something about reality that has a quality of truth, reality and authenticity. But that said, we do know as spectators, and all theories about documentary genres confirm that documentaries use all kinds of communicative strategies and they appeal not only to reason, but also to feelings and the more sensual dimensions of our reality.

Documentary films come, as both Plantinga (1997) and Nichols (2001) have shown, in many shapes and forms, and surely not all of these are mainly rhetorical, but even if they are rhetorical, narrative and emotional structures play an important role in our experience of such films. In the strong tradition of memory studies (see, for instance, van Dijck, 2007; Erll, 2011) we can furthermore see, that our memory is heavily mediated and influenced by our experience with both fiction and non-fiction. The link between narrative, emotion and memory is therefore central for our understanding of who we are, for our understanding of how mediated visual material and forms of representation influence our mind and body. Documentary forms and narratives become embodied visions and experiences in our minds -in line with experiences for ordinary 'real' life.

Documentary filmmakers have without any doubt always been aware that making films about reality in various ways combines factual evidence, arguments, documentation and elements of narrative, audio-visual style and creativity, appeal to imagination, identification etc., in sum a rhetoric of cognition and emotion. We know from theories of narrative (Bordwell, 1987; Gottschall, 2012) and theories of memory (Bluck, 2003; van Dijck, 2007; Erll, 2011) that emotional dimensions play an extremely important role in forming our social and cultural imagination. As cognitive neuroscientists like Antonio Damasio (1994, 1999) have pointed out: 'emotions and feelings are indispensable for rationality (...) Feelings, along with the emotions they come from, are no luxury. They serve as internal guides, and they help us communicate to others signals that can also guide them' (Damasio, 1994, xiii-xv).

Documentary genres are of course very much located in our mind as stories and arguments about affairs in the real world. We expect documentary to deal with real events, real people and actual problems of the world we live in. Fiction can do that as well, but in a more indirect way. When we watch fiction genres we know that we have to translate the fictional world we engage in to a story about something in reality. Fiction is based on a more indirect, metaphorical relation to reality. But even though this is part of the fictional stance towards reality, the actual experience of fiction draws on the same emotional and cognitive structures we use in real life. So fiction in a way is reality with a certain distance and reflexive dimension where we do at the same time react very directly to something in the film as we would to real life and negotiate and evaluate the film world in relation to our real world.

Our relation to documentary on the other hand is very much based on the primary expectation of a more direct relation with the real world. But again, depending on the actual sub-genre of documentary we are talking about, we use many of the same cognitive, emotional and narrative properties when experiencing and understanding the film. Cognitive, emotional and narrative properties cut across the distinction between fiction and non-fiction, they are universal human capacities although they have social and cultural variations in the way they are used and expressed. 


\section{Narrative and Emotions}

Cognitive film theory has pointed out how our minds and bodies are strongly pre-disposed for narrative structures and for certain emotional structures that are triggered when we are confronted with stories, images and human interaction. One might say that the ancient Greeks understood the connection between form, person and emotions when they defined good communication as creating a relation between ethos (personal credibility), logos (the power of arguments) and pathos (the power of emotions). But as many scholars in both cognitive film theory and linguistics have pointed out, the role of emotions - at least from a modern cognitive theoretical point of view-has been neglected in modern film and media theory and linguistics (Grodal, 2009; Lakoff \& Johnson, 1980; Plantinga 1997, 2009; Smith, 1995). In his book, Moving Viewers, from 2009, Carl Plantinga formulates it like this:

Why have effect and emotion in film viewing received relatively little attention in film studies (...) A strong strain of Western thought has considered emotion to be antithetical to reason and an obstacle to (...) critical thinking (...) Emotions are intimately tied to our cognition, inferences, evaluations and all of the other mental activities that accompany the viewing experience. Emotions and affects have implications for ideas (...) they play a role in the creation of both cultural and individual memory (Plantinga, 2009, pp. 5-6).

In the field of cognitive linguistics George Lakoff and Mark Johnson have argued convincingly for the role of images, narrative structures and metaphors in our language and communication in general. In Metaphors We Live By (1980) they argue against the notion of thoughts and concepts as just abstract entities and for an embodied understanding of the way we think. By showing the role of metaphors in all forms of communication they challenge the 'myth of objectivism and rationality' in Western thought. To understand how we think and reason, we also have to understand our body and emotions, and we have to understand that reason and argument is only one side of the coin in our embodied mind. In his book from 2008 on American politics, The Political Mind, Lakoff analyses the fundamental dimensions of political rhetoric, and he points to the often overlooked importance of narratives, metaphors and emotions:

According to Enlightenment reason was assumed to be conscious, universal, disembodied, logical, unemotional, value neutral, interest based and literal (...) but voters don't behave like that (...) Language gets its power because it is defined relative to frames, prototypes, metaphors, narratives, images and emotions. Part of its power comes from its unconscious aspects (Lakoff, 2008, p. 16)

According to cognitive film and media theory, narratives, emotions and images are not just stylistic dimensions bringing a film's story, characters and content to the front: they are important dimensions in our communication and interaction with the world on all levels. As for instance Plantinga points out: 'art emotions, the emotions and affects elicited by narrative film and other arts, have close affinities with the typical emotions of our extra filmic events' (Plantinga, 2009, p. 62 ). Not all documentaries have as strong a narrative structure as most mainstream fiction films. However, narrative structures and character identification is still a strong component in rather many documentaries. The point is that even though a film may not offer a very strong narrative structure in itself, spectators will use narrative frames to understand and relate to the film. We are 'storytelling humans' (Gottschall, 2012) and narrative is not just a stylistic feature in films, it is part of our mental toolbox and a way of making sense of what we see and experience.

This is why cognitive theory talks about narratives not just as stories in art and communication, but as part of our mental structure:

Complex narratives - the kind we find in anyone's life story, as well as in fairy tales, novels and dramaare made up of smaller narratives with very simple structures. Those structures are called "frames" or "scripts". Frames are among the cognitive structures we think with (...) the neural circuitry needed to create frame structures is relatively simple, and so frames tend to structure a huge amount of our thought (...) dramatic event structures are carried out by brain circuitry. The same event structure circuitry can be used to live out an action or narrative, or to understand the actions of others or the structure of the story. In addition, neural binding can create emotional experiences (...) narratives and frames are not just brain structures with intellectual content, but rather with integrated intellectualemotional content. (Lakoff, 2008, pp. 27-28)

\section{Ecological Narratives: Arguments and Emotional Politics}

Documentaries are divided into main prototypes that place the viewer differently in relation to the reality described and with regards to the overall rhetorical and narrative structure. I have argued for four such prototypes in my book Engaging With Reality. Documentary and Globalization (2014): the authoritative, the observational, the dramatized and the poeticreflexive (see Table 1). The categorization made here builds on categorizations suggested by for instance Bill 
Nichols (2001) and Carl Plantinga (1997). Many documentaries combine elements from different prototypes, but in all of them narrative and emotional dimensions play a crucial role, even though for instance the authoritative prototype is mostly based on arguments and rhetoric, the observational on very loose and sequential structures and the poetic reflexive often on more abstract visual associations and patterns.

But let me illustrate the differences and how narrative and emotional structures nevertheless play and important role in all types of films. In 2006 Davis Guggenheim made the ecological 'disaster'-documentary An Inconvenient Truth, which turned out to be a global success, and spurred a debate on global warming and other environmental issues that had been difficult to get on the agenda and find consensus about in the global political community. Part of the movie's success was no doubt that it had the political icon Al Gore as its main character and presenter of what in many ways was just a lavishly edited power point lecture. It is clearly an authoritative documentary, much like a public lecture, occasionally with a live audience, or off screen presentation accompanied by different types of visual material. As is usually the case with authoritative documentaries they present an awful lot of facts, either in the form of statistics, graphs, figures etc., by presenting voices of scientists and politicians or by presenting archive material on climate changes or environmental challenges and catastrophes. But the film also uses animation, irony and satire. All in all we have a film where the rhetorical, argumentative dimension is very strong, and where the data and arguments presented are meant to convince, persuade and activate audiences and politicians that may have doubts about the facts.

But even the facts and arguments presented here have powerful emotional dimensions, and the rhetoric and visual side of the film clearly uses that. At the same time Al Gore's personal charisma and credibility as former vice president is also used in an ironic way, when he introduces himself with the words: 'I used to be the next president of the USA'-referring back to the chaotic 2004 presidential election. But the emotional dimensions and the ethos connected to Al Gore as a politician is only one element in the film's use of emotions and in connecting pathos and logos. Throughout the film we see actual family footage from his childhood, his family life and from those places and the nature he experienced back then. Such sequences create a memory track and a particular narrative in audiences. They elicit partly nostalgic emotions and memories of a pre-climate warming situation, of a past, which-true or not-may seem to be idyllic and unproblematic compared to the dramatic images of the consequences of climate change today.

The authoritative narrative of a historical catastrophe scenario, which is the backbone for the arguments and the rhetoric of An Inconvenient Truth is thus embedded in a more personal narrative which is again connected to a network of metaphors and images that trigger our long term memory and feeling of loss connected to a more idyllic past, to which the present development is a threat. This personal, emotional narrative is deeply connected to the public agenda of the film, and part of this agenda is also that a more global mentality is called upon, not just in words, but in images of our globe seen over time from space. Al Gore directly comments on the first images of earth from outer space and a series of later images where the changes in the global environment are striking and scary. We see partly the same layers and mechanisms in function in another and rather different climate change film, Franny Armstrong's The Age of Stupid (2009). The main prototype used in this film is the dramatized, in the sense that part of the film takes place in 2055 in a fictional Arctic region, where the curator of The Global Archive, played by Pete Postlethwaite, is looking back on the events that led to the catastrophic end of our civilization.

Table 1. Basic Documentary Prototypes (Bondebjerg, 2014).

\begin{tabular}{|c|c|c|c|}
\hline Authoritative & Observational & Dramatized & Poetic-reflexive \\
\hline Epistemic authority & Epistemic openness & Epistemic-hypothetical & Epistemic-aesthetic \\
\hline Explanation-analysis & Observation-identification & Dramatization of factual reality & $\begin{array}{l}\text { Reality seen through aesthetic } \\
\text { form }\end{array}$ \\
\hline $\begin{array}{l}\text { Linearity, causality, rhetorical } \\
\text { structure }\end{array}$ & $\begin{array}{l}\text { Episodic, mosaic structure, } \\
\text { everyday life }\end{array}$ & $\begin{array}{l}\text { Reconstruction, narration, } \\
\text { staging (drama-doc, doc- } \\
\text { drama, mockumentary) }\end{array}$ & $\begin{array}{l}\text { Symbolic montage, meta- } \\
\text { levels, expressive, subjective } \\
\text { form }\end{array}$ \\
\hline $\begin{array}{l}\text { Q \& A, interview, witnesses, } \\
\text { experts, Authoritative VO }\end{array}$ & $\begin{array}{l}\text { Actor driven, human- } \\
\text { institutional life world }\end{array}$ & $\begin{array}{l}\text { Testing borders between reali- } \\
\text { ty and fiction }\end{array}$ & $\begin{array}{l}\text { Form driven reality experience, } \\
\text { the poetics of reality, framing } \\
\text { reality }\end{array}$ \\
\hline $\begin{array}{l}\text { Information, critique, } \\
\text { propaganda }\end{array}$ & $\begin{array}{l}\text { Documentation of lived reality, } \\
\text { social ethnology }\end{array}$ & $\begin{array}{l}\text { Narrative drive, reality driven } \\
\text { narrative. Media-reflexivity }\end{array}$ & $\begin{array}{l}\text { Challenging reality concepts } \\
\text { and traditional doc-forms }\end{array}$ \\
\hline
\end{tabular}


On the screen an opening statement of the film says: 'The future climate events portrayed in this film are based on mainstream scientific projections. Everything from the present day and the past is real news and documentary footage'. So the film signals, that the dramatized, semi-fictional future in the film is in fact based on science based predictions, and that all the rest of the film is based on documentary material and actual footage.

The film thus signals a sort of authoritative anchoring in reality, an intention of being taken seriously as documentation of factual events and causes behind these events. But as a whole, the film mixes a dramatized story of a future scenario, albeit told by a curator with direct access to a past reality, observational sequences of past lives, media footage and a very powerful visual construction of the birth and the death of earth. The film in fact starts with a very long and visually compelling sequence of the development of the universe from Big Bang till present day - a visual narrative of the greatest story and mystery ever told. The images are both fascinating and chilling, especially followed by the images of all the catastrophes following human neglect of the environment and its influence on our climate. Clips from news programmes and science documentaries underline this. As in An Inconvenient Truth the film creates a connection between an authoritative rhetoric of facts and arguments and a more emotional layer based on images of what this has done to life on this planet. This is very strongly underlined by the human narratives inserted throughout the film as small observational pieces of documentary. They give the film an everyday life dimension where we can identify with different people from different parts of the world that have lived facing the catastrophe the film predicts. Again narrative, facts and arguments are intertwined and in the end the curator destroys the archive and commits suicide. The emotional appeal to action is embedded in this film too, but with other means.

One might argue, following Richard Grusin (2010) that both films rely on what he calls a strategy of 'premediation', of a somewhat similar nature to fictional catastrophe narratives: affective, dramatized future narratives. Both films try in different ways to visualize a future that is scary and thus combines emotional experience and fact based predictions. But even though this is a special feature of such climate documentaries that try to illustrate abstract data and scientific arguments with personal and concrete experience, the interaction between emotions, personal and everyday experience and memories are always at work in documentaries. It takes a different form depending on the dominant prototype in the film in question. Authoritative, observational, dramatized and poetic forms of documentary offer different cognitive and emotional entry points to the experience of reality and combine narrative, emotion and memory in various ways.

\section{Historical Documentary: Memory and the Individual and Collective Dimensions of History}

As human beings we are programmed to narrative, narrative is one of the central ways of making sense of the real world and of things we encounter in audiovisual communication. But narratives are also linked to history, to our memory of the past, both our own and the collective past. We therefore see a strong fascination of not just narratives as such, but also for historical narratives. Documentary films about the past come in many forms, but they are often as popular with the audience as historical fiction films. Memory is an important dimension of our interaction with and communication about reality as narrative and emotions: memory is about constructing a coherent narrative about our past. Susan Bluck (2003) talks about the three functions of autobiographical memory: the preservation of the sense of being a coherent person over time; the strengthening of social bonds by being able to share personal memories and the use of past experiences to construct models to understand the inner worlds of self and others. Van Dijck in the book Mediated Memories in the Digital Age (2007) puts it like this:

Remembering is vital to our well-being, because without our autobiographical memories we would have no sense of past or future, and we would lack any sense of continuity. Our image of who we are (...) is never stable but it is subject to constant remodelling because our perceptions of who we are change along with our projections and desires of who we want to be. (p. 3)

Stories of the past play a role on a more personal, everyday level and are connected to stories family tell and share, to photo collections, diaries, memorabilia and today perhaps very much the stories we share on social media like Facebook or the movies we shoot and share on YouTube. Here strong ties are established between factual events and stories and emotions connected to them, but the fact that we often share this with a smaller or larger group of people indicates a broader social dimension of the personal, individual memory. But our personal memory is also connected to and influenced by stories about a wider local, national or regional past we are confronted with all the time: in history books, through fiction and non-fiction films, and through television. Historical narratives, and with them also historical documentary narratives, get their strength through their ability to make connections between the personal and the social, between the individual and the collective and between the factual and emotional. Van Dijck (2007) describes the two sides of memory in the following way: 
Personal cultural memory is the acts and products of remembering, in which individuals engage to make sense of their lives in relation to the lives of others and to their surroundings, situating themselves in time and place." (p. 6) "In a sociological sense, collective memory means that people must feel they were somehow part of a communal past, experiencing a connection between what happened in general and how they were involved as individuals. Adjusted to historiographical explanation, social memory constitutes the interface between individual and collective ordering of the past." (p. 10)

Documentary film is important for the shaping of our sense of a historical past and for our personal and collective memory. Like the ecological documentaries analysed above it is of course about getting history right, it is about presenting historical facts and realities. But in order to succeed in doing that the narrative and emotional dimension is important. Making the past visually present is a powerful way of narrating history. By bringing us somehow visually back to how the past looked, how the people then lived, felt and thought both fiction and non-fiction film and television can bring history to life as a both personal and collective narrative. Historical documentaries cannot replace the academic discipline of history, and scientific data and arguments will always be an important background for such film and television. Many of the widely watched historical documentaries are in fact made by historians that have founds ways of popularizing and visualizing history.

This is indeed the case with such television series as Simon Schama's A History of Britain (BBC, 2000-2002) or Kenneth Clarke's classic Civilization (BBC, 1966). Such series can be found in most national television cultures and they have become immensely popular with a very large audience. In those series we see both a strong presence of an authoritative narrator, but he is often placed in the middle of historical sites and evidences, and often dramatized versions of the past come to life through montage or direct reconstruction. Narrative and rhetorical structures are linked and through this linking and the impact of visuals our emotions and memories are activated and formed. More creative uses of memory and history in recent television have been dramatized formats sending contemporary people back in time in different ways. This is done for instance by recreating life as it was in 1900 in Channel 4's The 1900 House (1999), where a family relived life in the past for half a year-all under the instruction of historians. A simpler but very popular form is Who do you think you are? (2004-..., BBC) in which rather well known people dig into their past and learning about parts of their family history they did not know before. There is of course a certain element of showbiz to such series, but at the same time they do indicate how central history is for us and how the per- sonal and the collective, the factual and the emotional is intertwined also in these kinds of documentary stories.

\section{Cognitive, Narrative and Emotional Dimensions of Historical Documentary}

We can summarize what has been said so far by pointing to some of the central elements in memory as a cognitive, narrative and emotional activity. Memory is a cognitive, emotional dimension through which humans combine short-term memory and long-term memory. Memory generally works on several levels and is most strongly activated when 'data' from the past are condensed in narrative images and stories. In the works of Jan Assmann (2006) he distinguishes between communicative memory, understood as the everyday interaction between people in a given society involving reflections on their individual or the collective past, and the cultural memory, which is more institutionalized and often taken care of by special carriers of tradition, like museums, religions etc. What is not very visible in Assmann's work is however the role of mediated memories, the fact that today people are much more exposed to media content that triggers memory and at the same time to a larger degree have become producers of mediated memories through, for instance, social media (van Dijck, 2007). This is also taken up in Erll and Rigney's Mediation, Remediation and the Dynamics of Cultural Memory (2009) which argues that media of all sorts 'provide frameworks for shaping both experience and memory' (p. 1) and between the individual and collective dimensions of memory.

There is evidence suggesting that both narrative structures and emotional intensity is important for memory recall and presence in consciousness (Rosenstone, 2006; van Dijck, 2007; Glaser, Garsoffky, \& Schwan, 2009). The relation between subjective memory and identity and more general and external memory data is furthermore important for active memory. Cognitive theories of memory (Bluck, 2003) distinguish between 'explicit memory' (general semantic memory, contextual memory and auto-biographical memory) and 'procedural, implicit memory' (based on very basic nonconscious mechanisms). The intensity of memories and historical narratives and the amount of either positive emotional feelings or traumatic-negative feelings will influence the status and intensity of memory and historical understanding.

Historical documentaries use different narrative and visual strategies to create this 'feeling' of the historical past, an entry to a both factual understanding and emotional identification. We can identify some of them:

- Voice over narration and information-on screen/off screen: mixture of factual presentation and symbolic, metaphoric use of language; 
- Expert testimonies and experience testimoniesinterviews;

- Historical film footage;

- On site visual presentation of historical spaces, landmarks, buildings etc.;

- Use of dramatized reconstruction of historical events or persons, including types of programme based on re-enactment with audiences;

- Dramatizing still images of actual historical places, persons and events through visual effects (zooming, panning, montage);

- Drawing parallels between present times and historical event through montage and visual cues or through narrator-reflexive history;

- Use of poetic, narrative, dramatized and emotional aesthetics to position the audience in relation to the past:

o Marks of authenticity and factuality;

o Marks of heritage, the sublime, the grand, the tragic, the spectacular;

o Music and sound with direct emotional and memory effects.

\section{Ken Burns and the Narrative, Visual Recreation of World History and Personal Memory}

Let us look closer at two different, but still related examples of historical documentaries, Ken Burns and Lynn Novick's spectacular and ground breaking television series The War (PBS, 2007, 14 parts) about WW2 seen through the lens of Americans in four typical American cities, and Michael Grigsby's poetic and critical story of post-war Britain, The Time of Our Lives (1993), seen via the story of 85 year old Richard Harris and his family. Burns tells the story with the use of a clear, authoritative voice-over and with a combination of historical film footage and present voices representing the four towns. He also uses a clear narrativization technique and a special emotional and visual dramatization. Grigsby uses a basic observational strategy, following the family from the 85 year birthday celebration and into their lives, told by themselves, but he also uses a heavy and metaphorical montage of images and sounds to mix with the more personal stories.

In an explanation of his strategy, Ken Burns has said:

We chose to explore the impact of the war on the lives of people living in four American townsMobile, Alabama; Sacramento, California; Waterbury, Connecticut; and Luverne, Minnesota. Over the course of the film's nearly fifteen hours more than forty men and women opened their hearts to us about the war they knew-and which we, their inheritors, could only imagine. Above all, we wanted to honour the experiences of those who lived through the greatest cataclysm in human history by providing the opportunity for them to bear witness to their own history. Our film is therefore an attempt to describe, through their eyewitness testimony, what the war was actually like for those who served on the front lines, in the places where the killing and the dying took place, and equally what it was like for their loved ones back home. We have done our best not to sentimentalize, glorify or aestheticize the war, but instead have tried simply to tell the stories of those who did the fighting-and of their families. In so doing, we have tried to illuminate the intimate, human dimensions of a global catastrophe that took the lives of between 50 and 60 million people-of whom more than 400,000 were Americans. Through the eyes of our witnesses, it is possible to see the universal in the particular, to understand how the whole country got caught in the war; how the four towns and their people were permanently transformed; how those who remained at home worked and worried and grieved in the face of the struggle; and in the end, how innocent young men who had been turned into professional killers eventually learned to live in a world without war (Ken Burns quoted from http://www.pbs.org/the war/about_letter_from_producers.htm).

The quote clearly spells out the narrative strategy of Burns and his co-director, the way in which he combines micro history and macro history, the way in which he wants to combine collective historical facts and events with personal, subjective stories and points of view. He wants to speak to our memory through emotion and narrative and he is aware that the story he is telling is at the same time nationally specific-even local specific-and universal. If we take a closer look at Burns' documentary strategy we find that unlike most WW2 documentary narratives, there is no use of historical experts or high ranking military and political witnesses. The series clearly follows two main rhetorical strands:

- The authoritative voice-over narratorcombining all levels of the narrative and historical representation forms;

- Voices of the live witnesses - the men from the four American towns who fought in and survived WW2.

Underneath this special use of rhetorical voices, Burns furthermore uses a series of narrative and dramatic strategies:

- Recreating local everyday life through narrative and dramatic combination of still photos and/or original film footage; 
- Recreation of war events, battles etc. through narrative and dramatic combination of still photos and/or original film footage;

- Use of montage and cuts between past and present through persons and places in the local communities and the historical events.

By using these strategies the series is already speaking to us from a past that comes alive, not just through the voices of soldiers and family members that have a still living memory of how it was, but also by in fact bringing past footage alive in a more dense and dramatic way. In the very first sequences of part one, for instance, we are told the story of one of the survivors who-drunk and jealous-smashes into a bar to take revenge and then flees to enlist in the army. This story is told in voice-over by the main narrator speaking over still images from this past real spot that come alive by montage, image effects and music and sound effectsa piece of personal memory and history coming alive with all sorts of emotional cues.

This brings us to a third level of the series, the Visual and aesthetic strategies, some of which we have already dealt with in the above description of the opening sequence of the series, where the past comes alive as narrative and emotional space. The most important elements used are:

- Strong use of musical cues: original musical score (nostalgic-tragic) and popular period music to create memory of past;

- Factual authenticity of still photo and original film footage, mixed with dramatic and visual manipulation of images;

- New footage in colour with strong symbolic effects.

Burns is known for his ability to create drama, narrative and emotional structures in his documentary series, based on a creative use of montage and visual effects. Reconstructions and dramatizations are not made with the use of actors and contemporary settings and material, but by blowing life into historical material and combining it with live witnesses. His witnesses are not historical experts in the academic sense of the word, they are experts of everyday life history, they have lived the history told.

\section{Grigsby and the Narratives and Memories of Everyday Life}

The English filmmaker Michael Grigsby is also very much focused on ordinary people, their lives and their history. As a member of the British free cinema movement from the late 1950s he was, so to speak, born with a special interest in social and everyday life history. With his approach to documentary he wanted to combine social themes and the poetics of the everyday life. Unlike Burns he is at the same time a very classical, observational filmmaker. In all his films he lets reality and people speak for themselves, and he has explicitly turned against a tendency he sees in British film and television documentary to swamp everything with questions and commentary. In his documentaries he wants to create a reality space, where the viewers can experience and feel for themselves. At the same time he is very active in his editing of the film, in the montage of people, observations, talk and images so that they form a powerful social critique and symbol of society and history. In his comments to The Time of Our Lives (1993) he indicates his intention with the film like this: "Right from the start I wanted to make a film about the betrayal of the post-war dream. For all its impressionistic structure (...) there is a deep sense of the betrayals of the compassionate, caring society promised in 1945" (Grigsby as cited in Corner, 1996, pp. 123-124).

The film tells the post-1945 history of Britain through a network of family and friends surrounding the birthday of 85 year-old Richard Harris, it is in fact a kind of observational montage of family voices and stories. The film doesn't follow a linear chronological story; on the contrary, we start in the present day and keep moving back and forth in the life of Harris and his family and a broader historical context. The family stories are combined with the social and cultural history of Britain since 1945, and these two strands of stories and history comment on each other and are intertwined. Harris represents the traditional British working class, and we follow his story as a migrant from poor Ireland to the richer English industrial centre. But his family story at the same time covers younger generations with upward mobility and new life styles.

But underneath the observational stories of Richard and other family members Grigsby uses contemporary and historical montage of music, radio, television and film to contextualize the family story. He mixes public and private history-collective history resonating in individual history. In this way he does in a very powerful way address the viewer's memory, by linking personal and public history elements and layers. The combination creates a double narrative, which not only makes the viewer reflect on the link and combination of macro and micro history, but also establishing specific emotional qualities to both dimensions of history.

This is strongly underlined and supported by the audio-visual strategies of Grigsby, the way in which he reconstructs and manipulates the contemporary or historical footage he uses. He is highly symbolic in his visual sequences using dramatization of both sound and images and thus creating a space for living historical memory. In, for instance, a rather dramatic sequence filmed inside St. Paul's Cathedral, we hear texts read aloud, speeches and sounds of war, illustrating the his- 
tory of WW2. Other instances involve use of radio interviews with politicians or others, pointing towards contrasting promises made with the realities that followed. In his efforts to speak to both the viewer's hearts and minds, Grigsby puts the ordinary lives and voices of British working class people at the centre of his films. At the same time he uses all the narrative, visual, poetic and dramatic forms to speak to our memory and emotions, to create a rich documentary space of identification with a past coming alive in front of us.

\section{Concluding Perspectives}

Humans are genetically, biologically and socially storytelling animals: narrative structures are a fundamental way of experiencing, exploring and thinking about reality. Stories come to us with invitation to both cognitive and emotional responses and activities and those two dimensions are linked intimately in real life, fiction and documentary forms. Non-fiction genres have different variations of rhetorical and narrative structures and they follow patterns of social and psychological involvement that are also used in real life experience and interaction. Emotions cannot be separated from reason and rationality, although emotions can of course have a negative impact on communication and reasoning.

Emotional layers in documentaries appear through narrative structures, through character identification, through audio-visual effects, but they are also directly connected to content and themes with links to real life, to our decisions to act directly or indirectly when confronted with human and social problems. As Plantinga puts it:

In movie spectatorship as in the rest of life, the repetition of elicited emotions and judgements may solidify ways of thinking and feeling. It is through the elicitation of emotion in relation to moral and ideological judgement that a film may have its most significant ideological force.' (Plantinga, 2009, p. 203)

The role of narrative, emotion and memory in different forms of documentary film and television is important for further studies. Even though emotion and memory theories have played a certain role in documentary theory already, there is a need to expand this kind of approach and include cognitive studies of narrative, emotion and memory. As for instance van Dijck has pointed out, mediated memories have a widespread function in our culture and society, and we both have embodied aspects of narrative, emotion and memory and embedded aspects. Documentary narratives speak both to our private memory and story bank, to those structures through which we have narrative and emotional dispositions, and which help us construct a feeling of continuity between our past, present and future. But this personal and private memory is at the same time embedded in a media culture of a public and collective kind.

\section{Acknowledgements}

Some parts of this article were presented in earlier forms at a conference in the Screening European Heritage Network, Leeds University, November 2012, and at the Visible Evidence Conference in Canberra, December 2012. The author wants to thank the organisers for accepting the papers and for the comments from participants.

\section{Conflicts of Interest}

The author declares no conflict of interest.

\section{References}

Assman, J. (2006). Communicative and Cultural Memory. In A. Erll \& A. Nünning (Eds.), Cultural Memory Studies. An International and Interdisciplinary Handbook. Berlin/New York: William de Gruyter.

Bluck, S. (2003). Autobiographical Memory: Exploring its Functions in Everyday Life. Memory, 11(2):113-123.

Bondebjerg, I. (2014). Engaging With Reality. Documentary and Globalization. Bristol/Chicago: Intellect.

Bordwell, D. (1987). Narration in the Fiction Film. Minneapolis, MN: University of Minnesota Press.

Bordwell, D., Thompson K. (2001). Film Art. An Introduction (6th ed.). New York, NY: McGraw Hill.

Brothers, L. (1997). Friday's Footprint. How Society Shapes the Human Mind. Oxford, UK: Oxford University Press.

Corner, J. (1996). The art of Record. Manchester, UK: Manchester University Press.

Damasio, A. (1994). Descartes' Error. Emotion, Reason and the Human Brain. New York, NY: Vintage Books.

Damasio, A. (1999). The Feeling of What Happens. Body, Emotions and the Making of Consciousness. New York, NY: Vintage Books.

Erll, A. (2011). Memory in Culture. Basingstoke, UK: Palgrave Macmillan.

Erll, A., Rigney, A. (2009). Mediation, Remediation, and the Dynamics of Cultural Memory. Berlin/New York: Walter de Gruyter.

Fauconnier, G., Turner, M. (2002). The way we think. Conceptual Blending and the Mind's Hidden Complexities. New York, NY: Basic Books.

Glaser, M., Garsoffky, B., Schwan, S. (2009). Narrative Based Learning: Possible Benefits and Problems. Communications, 34(4), 429-447.

Gottschall, J. (2012). The Storytelling Animal. How Stories make us Human. New York, NY: Mariner Books.

Grodal, T. (2009). Embodied Visions. Evolution, Emotion, Culture and Film. Oxford, UK: Oxford University Press. 
Grusin, R. (2010). Premediation: Affect and Mediality after 9/11. Basingstoke, UK: Palgrave MacMillan.

Lakoff, G. (2008). The Political Mind. New York, NY: Tantor Media.

Lakoff, G., Johnson, M. (1980). Metaphors we live by. Chicago, IL: Chicago University Press.

Lakoff, G., Johnson, M. (1999). Philosophy in the Flesh. The Embodied Mind and It's Challenge to Western Thought. New York, NY: Basic Books.

Nichols, B. (2001). Introduction to Documentary. Bloomington, IN: Indiana University Press.

Plantinga, C. (1997). Rhetoric and Representation in Nonfiction Film. Cambridge, UK: Cambridge University Press.

Plantinga, C. (2009). Moving Viewers. American Film and the Spectator's Experience. Los Angeles, CA: University of California Press.

Plantinga, C., Smith, G. (1999). Passionate Views. Film, Cognition and Emotion. Maryland: John Hopkins University Press.
Rosenstone, R. (2006). History on Film-Film on History. London, UK: Longman.

Smaill, B. (2010). The Documentary. Politics, Emotion, Culture. Basingstoke: Palgrave Macmillan.

Smith, M. (1995). Engaging Characters. Fiction, Emotion and the Cinema. Oxford, UK: Clarendon Press.

Turner, M. (1998). The Literary Mind. The Origins of Thought and Language. Oxford, UK: Oxford University Press.

Turner, M. (2006). The Artful Mind. Cognitive Science and the Riddle of Human Creativity. Oxford, UK: Oxford University Press.

van Dijck, J. (2007). Mediated Memories in the Digital Age. Stanford, CA: Stanford University Press.

Westen, D. (2007). The Political Brain. The Role of Emotion in Deciding the Fate of the Nation. New York, NY: PublicAffairs.

Zerubavel, E. (1999). Social Mindscapes. An Invitation to Cognitive Sociology. Cambridge, MA: Harvard University Press.

\section{About the Author}

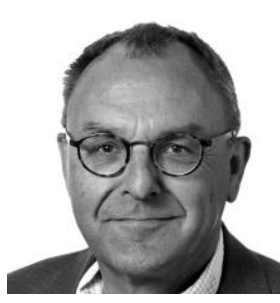

\section{Dr. Ib Bondebjerg}

Ib Bondebjerg is Professor of film and media studies, Department of Media, Cognition and Communication, University of Copenhagen and was director of the Centre for Modern European Studies (2008-2011). $\mathrm{He}$ is currently co-directing the European research project Mediating Cultural Encounters Through European Screens (2013-2016, www.mecetes.uk.co) and co-editor of the books series Palgrave European Film and Media Studies He has published widely on European film and media and documentary film. His most recent book is Engaging with Reality: Documentary and Globalization (2014). 